\title{
Formation of 3-methyl-1,2,3-butanetricarboxylic acid via gas phase oxidation of pinonic acid - a mass spectrometric study of SOA aging
}

\author{
L. Müller ${ }^{1}$, M.-C. Reinnig ${ }^{1}$, K. H. Naumann ${ }^{2}$, H. Saathoff ${ }^{2}$, T. F. Mentel $^{3}$, N. M. Donahue ${ }^{4}$, and T. Hoffmann ${ }^{1}$ \\ ${ }^{1}$ Johannes Gutenberg-Universität, Institute for inorganic Chemistry and analytical Chemistry, Duesbergweg 10-14, \\ 55128 Mainz, Germany \\ ${ }^{2}$ Karlsruhe Institute of Technology Institute for Meteorology and Climate Research (IMK-AAF), \\ Hermann-von-Helmholtz-Platz 1, 76344 Eggenstein-Leopoldshafen, Germany \\ ${ }^{3}$ Forschungszentrum Jülich GmbH, ICG-2: Troposphäre, 52425 Jülich, Germany \\ ${ }^{4}$ Carnegie Mellon University Department of Chemical Engineering, 5000 Forbes Avenue, Pittsburgh, PA 15213-3890, USA
}

Correspondence to: T. Hoffmann (hoffmant@uni-mainz.de)

Received: 15 June 2011 - Published in Atmos. Chem. Phys. Discuss.: 6 July 2011

Revised: 8 January 2012 - Accepted: 18 January 2012 - Published: 8 February 2012

\begin{abstract}
This paper presents the results of mass spectrometric investigations of the $\mathrm{OH}$-initiated oxidative aging of $\alpha$-pinene SOA under simulated tropospheric conditions at the large aerosol chamber facility AIDA, Karlsruhe Institute of Technology. In particular, the $\mathrm{OH}$-initiated oxidation of pure pinic and pinonic acid, two well-known oxidation products of $\alpha$-pinene, was investigated. Two complementary analytical techniques were used, on-line atmospheric pressure chemical ionization/mass spectrometry (APCI/MS) and filter sampling followed by liquid chromatography/mass spectrometry (LC/ESI-MS). The results show that 3-methyl1,2,3-butanetricarboxylic acid (MBTCA), a very low volatile $\alpha$-pinene SOA product and a tracer compound for terpene SOA, is formed from the oxidation of pinonic acid and that this oxidation takes place in the gas phase. This finding is confirmed by temperature-dependent aging experiments on whole SOA formed from $\alpha$-pinene, in which the yield of MBTCA scales with the pinonic acid fraction in the gas phase. Based on the results, several feasible gas-phase radical mechanisms are discussed to explain the formation of MBTCA from $\mathrm{OH}-$ initiated pinonic acid oxidation.
\end{abstract}

\section{Introduction}

Atmospheric organic aerosol (OA) has major impacts on climate, air quality and human health (Kanakidou et al., 2005; Nel, 2005). A major fraction of the OA load in the atmo- sphere is attributed to secondary organic aerosol (SOA) (de Gouw et al., 2005). SOA is formed via the gas phase oxidation of volatile organic compounds (VOCs) by atmospheric oxidants such as ozone, $\mathrm{OH}$-radicals, and $\mathrm{NO}_{3}$-radicals. The oxidation results in the formation of semi- and low-volatile compounds, which may condense on existing particles or undergo new particle formation (nucleation) (Kroll and Seinfeld, 2008). A vast number of different organic species is involved in the formation and evolution of SOA, which is driven by gas-phase, particle-phase and heterogeneous chemistry. Therefore, SOA can be described as a highly dynamic multiphase chemical system (Hallquist et al., 2009; Jimenez et al., 2009; Kiendler-Scharr et al., 2009; Kroll and Seinfeld, 2008; Robinson et al., 2007). Despite some progress in the understanding of OA chemistry and SOA chemistry in particular, there is still a knowledge gap preventing an accurate description of SOA yields, SOA evolution and its climatic impact. One poorly understood aspect is atmospheric aging. Aging is the chemical evolution of SOA in the atmosphere on timescales of aerosol lifetimes (5-12 days) (Molina et al., 2004; Robinson et al., 2007; Rudich et al., 2007). Oxidation by atmospheric reactants alters the chemical composition of SOA compounds, which can in turn affect physicochemical properties such as volatility, hygroscopicity or CCN activity (George et al., 2009; Rudich et al., 2007; Shilling et al., 2007). 
Recent studies describe SOA formation and evolution in a two-dimensional framework of compound volatility versus oxidation state (Donahue et al., 2009; Jimenez et al., 2009). Within this framework three types of chemical processing are discussed: fragmentation, functionalization, and oligomerization. Fragmentation will ultimately lead to the degradation of a compound to smaller, more volatile products (e.g. $\mathrm{CO}_{2}$ ); functionalization, however, will basically introduce more oxygen containing groups and lead to the formation of less volatile oxygenated organic aerosol (OOA) (e.g. organic acids, peroxides) (Reinnig et al., 2009; Szmigielski et al., 2007). Fragmentation typically also involves addition of oxygen containing groups: volatile species can be eliminated from a larger molecule, while the volatility of the remaining part is decreasing by further functionalization reactions (Kroll et al., 2009). The third possible reaction pathway is the formation of oligomers, which means the combination of smaller molecules to a larger one. In these oligomerization reactions less volatile compounds (esters, lactones, etc.) will almost always be formed (Gao et al., 2010; Kalberer et al., 2004; Müller et al., 2008, 2009; Yasmeen et al., 2010).

In the past two decades it was shown in a multiplicity of studies that organic acids are major products of ozonolysis and $\mathrm{OH}$-initiated reactions of terpenes (Hatakeyama et al., 1991; Hatakeyama et al., 1989; Hoffmann et al., 1997, 1998, 2002; Warnke et al., 2006; Yu et al., 1999). Recent studies by Szmigielski et al. (2007) identified the highly oxidized tricarboxylic acid 3-methyl-1,2,3-butanetricarboxylic acid (MBTCA) being a new and most relevant tracer compound for atmospheric terpene SOA. This tracer was first detected in aerosol samples from Amazonia and Belgium (Kubatova et al., 2002; Kubatova et al., 2000). Very recently the potential use of 1,2,3-butanetricarboxylic acid as SOA oxidation tracer was also demonstrated for long time field observations conducted by Zhang et al. (2010).

Besides the question of the chemical nature and volatility of the aging products, a central question is in which phase the processing takes place. Heterogeneous $\mathrm{OH}$ chemistry and photochemistry in the particle phase have been suggested as important processes (George et al., 2007; Walser et al., 2007). However, the gas-phase oxidation of semi-volatile compounds might also contribute to the aging of SOA compounds. Oxidation of semi-volatile compounds (SVOCs) in the gas phase has already been discussed in case of the aging of primary organic aerosol (POA) and the formation of oxygenated aerosol (OOA) (Donahue et al., 2006; Kroll et al., 2007; Miracolo et al., 2010; Rudich et al., 2007). However, not much is known about oxidative aging on a molecular level, e.g. for biogenic SOA. Due to the large number of semi-volatile organic compounds existing in SOA, it is most likely that gas-phase chemistry is at least of some importance (Shrivastava et al., 2006). Certainly, it is not useful or even possible to identify every oxidation pathway of each single SOA compound; however, for a process-level understanding of the evolution of SOA it is certainly valuable to identify

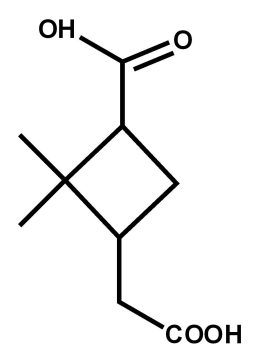

(a)

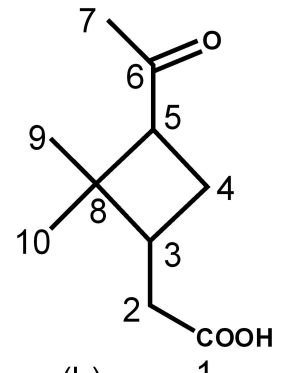

(b)
1

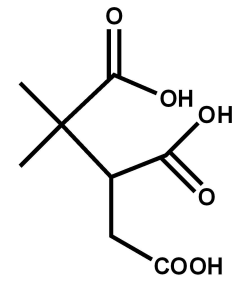

(c)
Fig. 1. Structure of (a) pinic acid $\left(\mathrm{M}_{w} 186 \mathrm{da}\right)$, (b) pinonic acid $\left(\mathrm{M}_{w} 184 \mathrm{da}\right)$ and (c) MBTCA $\left(\mathrm{M}_{w} 204 \mathrm{da}\right)$.

the dominant products and oxidation pathways, and to elucidate these in detail. In addition, the identification of individual compounds at different steps in the reaction chain bears the potential to identify tracer compounds to understand origin and chemical fate of organic aerosols in field measurements. For this purpose the oxidation of single SOA compounds have to be investigated under controlled atmospheric conditions.

The aim of this work was the investigation of the $\mathrm{OH}-$ initiated oxidative aging of $\alpha$-pinene SOA under simulated tropospheric conditions at the large aerosol chamber facility AIDA, Karlsruhe Institute of Technology (Saathoff et

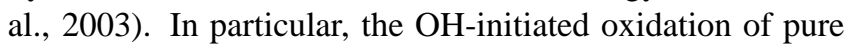
pinic (Fig. 1a) and pinonic acid (Fig. 1b) aerosol was investigated to get a detailed insight into the aging chemistry on a molecular level. The formation of 3-methyl-1,2,3butanetricarboxylic acid (MBTCA) was chosen as a single model process for SOA aging and was investigated under controlled experimental conditions. By using the experimental results presented here, Zhang et al. (2010) could explain the appearance and temporal behavior of MBTCA concentrations in the troposphere during long time SOA observations.

\section{Experimental}

\subsection{The AIDA aerosol and cloud chamber}

The AIDA aerosol and cloud chamber at Karlsruhe Institute of Technology (Saathoff et al., 2003) was used to investigate the oxidation of pinic and pinonic acid aerosol by $\mathrm{OH}$ radicals at a pressure of $(1003 \pm 1) \mathrm{hPa}$, a temperature of $(283.1 \pm 0.1) \mathrm{K}$, and a relative humidity of $(36 \pm 2) \%$. The AIDA chamber is made of aluminum. It has a total volume of $84.5 \mathrm{~m}^{3}$, an upright cylindrical shape with a total surface area of $103 \mathrm{~m}^{2}$, and a cross sectional area of $12.6 \mathrm{~m}^{2}$. Before each experiment the AIDA chamber was evacuated to typically $1 \mathrm{~Pa}$ total pressure, flushed two times with $10 \mathrm{hPa}$ of synthetic air and filled to atmospheric pressure $(\sim 1000 \mathrm{hPa})$ with humidified synthetic air (low hydrocarbon grade, Basi). Pinic acid and pinonic acid aerosol was added to the chamber 
by nebulizing aqueous solutions using a home built nebulizer similar to a commercial system (TSI, Model 3079). The aqueous solutions dispersed had concentrations of $0.2 \mathrm{wt} \%$ for pinic and $0.49 \mathrm{wt} \%$ for pinonic acid (98\%, Aldrich).

In addition to the pure acid experiments, some SOA aging experiments were performed with an excess concentration of ozone and step-wise addition of the organic reactant. SOA particles were generated by reacting (1S)-(-)$\alpha$-pinene (99\%, Aldrich) with ozone in the dark. In most experiments ozone was first filled into the chamber to measure the level of background particle formation before the terpene was added. The background particles were formed typically $15-20 \mathrm{~min}$ after the addition of ozone in varying number concentrations but with negligible mass concentrations. Ozone was generated by a silent discharge generator (Semozon 030.2, Sorbios) in mixing ratios of about $3 \%$ in pure oxygen $(99.998 \%$ ) and added to the chamber either directly or more typically after dilution to about $1 \%$ in a 11 glass bulb which was flushed into the chamber with a flow of 5 SLM synthetic air. Defined amounts of the terpenes were added by evaporating $1-4 \mathrm{hPa}$ into 1 and 21 glass bulbs, diluting them with synthetic air, and flushing the contents into the chamber with 10 SLM synthetic air for $3 \mathrm{~min}$. A mixing fan in the chamber was running during all experiments providing typical mixing time of less than $3 \mathrm{~min}$. Particle size distributions were measured with differential mobility analysers (SMPS, TSI, 3071) and particle number concentrations were determined with condensation particle counters (CPC, TSI, 3022A, 3776). Particle mass concentrations were calculated by integration of the measured size distributions (SMPS) and using a SOA particle density of $1.25 \mathrm{~g} / \mathrm{cm}^{3}$ (Saathoff et al., 2009). For crystalline pinic acid the density has been determined to $1.21-1.23 \mathrm{~g} \mathrm{~cm}^{-3}$. For cis pinonic acid the density is $1.22-1.23 \mathrm{~g} \mathrm{~cm}^{-3}$ (Krc, 1953; Vanderhoff et al., 1986)

\section{$2.2 \quad$ OH-source}

$\mathrm{OH}$ radicals were generated in the AIDA chamber by continuously adding 30 SCCM of $1000 \mathrm{ppm}$ tetramethylethylene (TME) in pure nitrogen to the chamber $(\sim 21 \mathrm{ppb} / \mathrm{h})$ filled with ozone levels between 400 and $700 \mathrm{ppb}$. Reaction between ozone and TME leads to almost quantitative formation of one $\mathrm{OH}$ radical and one acetone molecule per molecule TME reacted. Resulting OH radical concentrations can be calculated by analysing the observed concentration profiles for ozone, 3-pentanol, pinonaldehyde and acetone using the master chemical mechanism (MCM 3.1, http://mcm.leeds.ac.uk/MCM/home.htt, (Jenkin et al., 2003; Saunders et al., 2003). Ozone was measured with an ozone monitor (O3-41M, Environment) connected to the chamber via a Teflon tube. Water concentrations were measured with a frost point mirror hygrometer (373LX, MBW) and in situ by absorption spectroscopy using a tuneable diode laser at $1370 \mathrm{~nm}$. The concentrations of trace gases like $\alpha$-pinene, 3 pentanol, pinonaldehyde and acetone were measured with a
Proton Transfer Reaction Mass Spectrometer (PTR-MS, Ionicon). The PTR-MS was sampling from the AIDA chamber via a stainless steel tube ( $4 \mathrm{~mm}$ inner diameter) through a Teflon filter (PTFE, $0.2 \mu \mathrm{m}$ pore size, Satorius) in the thermostated housing, which could also be bypassed. The filter removed aerosol particles from the sample flow to avoid possible evaporation of aerosol particles in the inlet of the PTRMS. The PTR-MS measurements were taken with a time resolution of 5 min.

\subsection{On-line APCI-MS}

The APCI/MS on-line technique used here (Hoffmann et al., $1998,2002)$ allows a direct introduction of the reaction mixture into the ion source of the mass spectrometer. Possible analytical artefacts of filter-based methods, such as incomplete analyte extraction or reactions during sampling or extraction can thus be avoided. Furthermore, on-line measurements can provide temporally resolved insights in the formation of secondary organic aerosol. On the other hand the online technique provides no separation of the analytes before ionisation and detection. Therefore, the results can be affected by isobaric interferences and an unambiguous identification of single compounds is often difficult. Consequently, both methods were applied to the same set of experiments.

On-line-APCI/MS and -MS/MS analyses were performed using a LCQ ion trap mass spectrometer (Finnigan MAT, USA) with a modified atmospheric pressure chemical ionization source in the negative ion mode (Finnigan MAT, USA). The instrument was connected to the simulation chamber by an electropolished stainless steel tube of $6 \mathrm{~mm}$ inner diameter. To remove the gas phase from the generated particle phase a charcoal-filled diffusion denuder was usually connected between the AIDA chamber and ion source, but the denuder could also be bypassed. The APCI parameters were set to: $2 \mu \mathrm{A}$ discharge current, $350^{\circ} \mathrm{C}$ vaporizer temperature, $200^{\circ} \mathrm{C}$ capillary temperature, $-7.8 \mathrm{~V}$ capillary voltage, $16.4 \mathrm{~V}$ lens voltage. The sheath gas flow rate was set to 5 units (arbitrary units defined by the instrument software). The APCI/MS/MS experiments were recorded at different collision energies and helium was used as collision gas.

\subsection{Sample collection preparation and quantitative HPLC-ESI/MS measurements}

Particulate ozonolysis products were collected on $70 \mathrm{~mm}$ PTFE coated quartz fiber filters (PALLFLEX T60A20, Pall Life Science, USA) with a flow of $10.0 \mathrm{~L} \mathrm{~min}^{-1}$ and a sampling time of 1 hour. The total sample volume was $0.6 \mathrm{~m}^{3}$. The filter samples collected were stored at $-20^{\circ} \mathrm{C}$ until analysis. For HPLC ESI-IT/MS investigations the filter samples were extracted two times for about $30 \mathrm{~min}$ with $2 \mathrm{~mL}$ extraction agent (methanol/water 1:10 v/v) by sonification. After filtration (Sartorius Minisart SRP4, PTFE-membrane $0.45 \mu \mathrm{m})$ the unified extracts were concentrated under a 
gentle stream of nitrogen and heating $\left(60^{\circ} \mathrm{C}\right)$ until a total volume of $0.2 \mathrm{~mL}$ remained. The filter extracts were analysed via HPLC-ESI-IT/MS ${ }^{n}$ using an HCT-Plus ion trap mass spectrometer (Bruker-Daltonics GmbH, Bremen, Germany) equipped with a HPLC-System (Agilent 1100 series, auto sampler, gradient pump and degasser, Agilent Technologies $\mathrm{GmbH}$, Germany) and a Pursuit XRs 3 C8 $150 \mathrm{~mm} \times 2.0 \mathrm{~mm}$ column with $3 \mu \mathrm{m}$ particle size (Varian, Germany).The eluents were HPLC grade water (Milli-Q water system, Millipore, Bedford, USA) with $0.1 \%$ formic acid and $2 \%$ acetonitrile (eluent A) and acetonitrile with $2 \%$ water (eluent B). The gradient of the mobile phase, with a flow of $0.2 \mathrm{~mL} \mathrm{~min}^{-1}$, was chosen as follows: Starting with $0 \% \mathrm{~B}$, gradient to $100 \% \mathrm{~B}$ in $30 \mathrm{~min}$, isocratic for $5 \mathrm{~min}$ and gradient to $0 \% \mathrm{~B}$ in $5 \mathrm{~min}$. The column was equilibrated at $0 \% \mathrm{~B}$ for $20 \mathrm{~min}$. The LC system was directly connected to the electrospray ion source with the following setup: nebuliser pressure 2200 mbar, dry gas flow $10 \mathrm{~L} \mathrm{~min}^{-1}$, dry gas temperature $365^{\circ} \mathrm{C}$, spray voltage $4500 \mathrm{~V}$. The ion optic of the mass spectrometer, operated in the negative ion mode, was optimized for adipic acid (negative ion mode $\mathrm{m} / \mathrm{z} 145$ ). The analytes were quantified using an external calibration method. For that purpose five MBTCA (MBTCA standard compound was provided by Magda Claeys University of Antwerp, Belgium) standard solutions in acetonitrile of $0(<0.001) \mu \mathrm{g} \mathrm{mL}^{-1}$ (blank); $0.28 \mu \mathrm{g} \mathrm{mL}^{-1} ; 1.4 \mu \mathrm{g} \mathrm{mL}^{-1}$; $1.75 \mu \mathrm{g} \mathrm{mL}^{-1} ; 7 \mu \mathrm{g} \mathrm{mL}^{-1}$ were used.

\subsection{Results and discussion}

The results of the on-line APCI/MS investigations of the particle phase for the hydroxyl radical oxidation of pure pinic and pinonic acid aerosol are summarized in Figs. 2 and 3. The on-line APCI-MS system is an appropriate method to observe changes in the chemical composition of organic compounds in the particle phase. It has a high time resolution and due to its soft ionization provides species resolved information. For acidic compounds such as organic acids the use of $\mathrm{APCI}(-)$ usually results in the formation of [M$\mathrm{H}]^{-}$-ions. Figure 2 shows the APCI(-)/MS mass traces of pinic acid ( $m / z 185$, green line), pinonic acid $(m / z 183$, red line) and MBTCA $(\mathrm{m} / z, 203$, blue line). Additionally the temporal development of particle mass concentration determined from measured size distributions (SMSP) is plotted in the graph as black dots. The hatched areas mark the periods while pinic acid (00:00-00:20 h) and cis-pinonic acid aerosol (03:15-03:40 h, 04:40-05:20 h) were added to the chamber. The two areas indicated by arrows (addition of TME) show the period while $\mathrm{OH}$-radicals were produced.

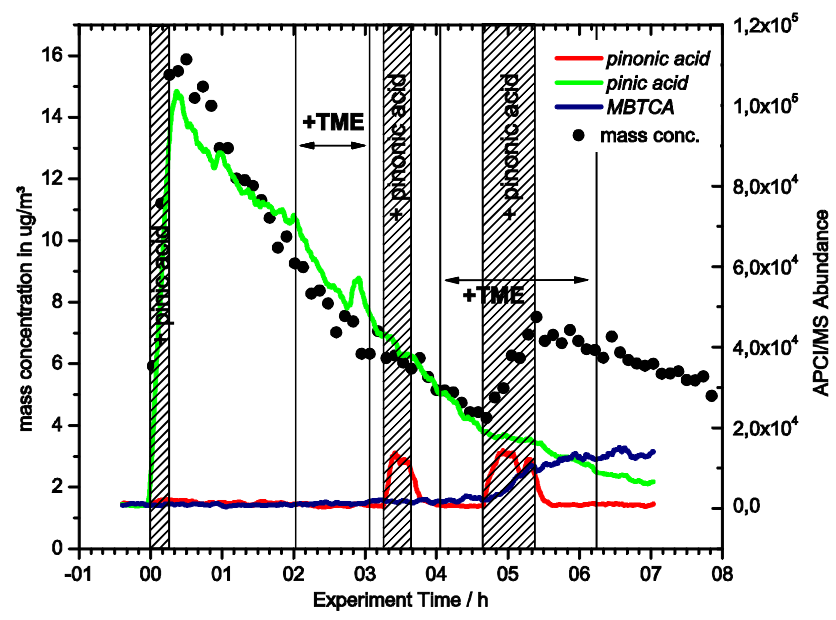

Fig. 2. APCI(-) mass traces of pinic acid $(m / z 185$ green), pinonic acid $(m / z 183 \mathrm{red})$, MBTCA $(m / z 203$ blue), particle mass concentration measured by SMPS (filled dots); The hatched area marks the addition of pinic acid and pinonic acid, the borders marked with arrows (+TME) is the time of $\mathrm{OH}-$ production.

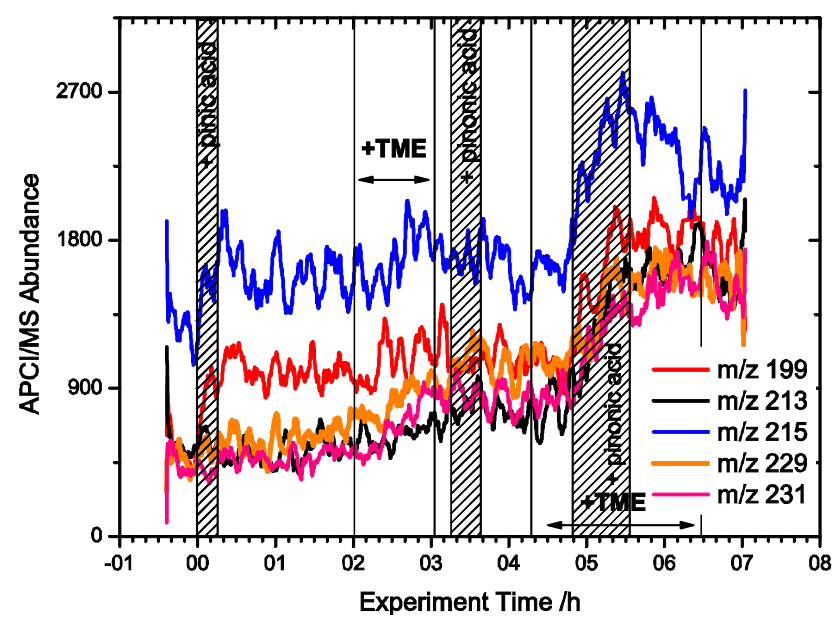

Fig. 3. APCI(-) mass traces of $m / z 199$ (red), $m / z 213$ (black), $m / z 215$ (blue); $m / z 229$ (yellow); $m / z 231$ (pink), the hatched area marks the addition of pinic acid and pinonic acid, the time period marked with arrows (+TME) is the time of hydroxyl radical addition.

\subsection{Wall loss in the simulation chamber and gas phase concentration of pinonic acid}

An interesting feature shown in Fig. 2 is temporal behavior of the mass traces of pinonic and pinic acid, which differ significantly from each other. As expected, the mass trace $m / z 185$ increased in coincidence with particle mass concentration (Fig. 2, black dots) during the addition of pinic acid aerosol to the chamber. Both signals start to decrease simultaneously after the addition of the pinic acid was stopped. When pinonic acid aerosol was added to the chamber $(03: 15-03: 40)$ 
Table 1. Values for pinonic acid concentration calculations.

\begin{tabular}{lllll}
\hline & Input values & SIMPOL (300 K) & SIMPOL (283 K) & Bilde \& Pandis (2001) 283 K \\
\hline input rate pinonic acid $^{\mathrm{a}}$ & $3.3 \times 10^{-2} \mu \mathrm{g} \mathrm{m}^{-3} \mathrm{~s}^{-1}$ & & & \\
gas phase wall loss $^{\mathrm{b}}$ & $2.0-4.0 \times 10^{-4} \mathrm{~s}^{-1}$ & & \\
$C^{*}$ (pinic acid) & $1 \times 10^{1} \mu \mathrm{g} \mathrm{m}^{-3}$ & $1 \times 10^{1} \mu \mathrm{g} \mathrm{m}^{-3}$ & $1 \mu \mathrm{g} \mathrm{m}^{-3}$ & $0.3 \mu \mathrm{g} \mathrm{m}^{-3}$ \\
$C^{*}$ (pinonic acid) & $1 \times 10^{3} \mu \mathrm{g} \mathrm{m}^{-3}$ & $1 \times 10^{3} \mu \mathrm{g} \mathrm{m}^{-3}$ & $2 \times 10^{2} \mu \mathrm{g} \mathrm{m}^{-3}$ & $5.2 \mu \mathrm{g} \mathrm{m}^{-3 \mathrm{~d}}$ \\
$C^{*}$ (MBTCA) & $1 \times 10^{-3} \mu \mathrm{g} \mathrm{m}^{-3}$ & $1 \times 10^{-2} \mu \mathrm{g} \mathrm{m}^{-3}$ & $5 \times 10^{-4} \mu \mathrm{g} \mathrm{m}^{-3}$ & \\
organic mass loading & $16 \mu \mathrm{g} \mathrm{m}^{-3}$ & & & \\
\hline
\end{tabular}

${ }^{a}$ determined from particle mass concentration ${ }^{\mathrm{b}}$ Saathoff et al. (2009) ${ }^{\mathrm{c}}$ measured initial particle mass concentration ${ }^{\mathrm{d}} 7 \times 10^{-5}$ Pa estimated for $296 \mathrm{~K}$, Bilde and Pandis (2001)

the mass trace $m / z 183$ showed a similar but even more pronounced effect. Although pinonic acid was added as an aerosol, almost no increase in the particle mass concentration (Fig. 6, black dots) could be observed and the mass trace $m / z 183$ rapidly disappeared after the pinonic acid aerosol addition was stopped. These observations can be easily understood if one considers the aluminum walls of the AIDA vessel to act as an efficient sink for certain gaseous organic compounds, i.e. organic acids, by irreversible uptake on the walls of the chamber. In previous studies the first-order loss rate has been observed in a range of $2.0-4.0 \times 10^{-4} \mathrm{~s}^{-1}$ (Saathoff et al., 2009). Simulations based on the aerosol behaviour code COSIMA (Naumann, 2003) show that under such conditions the wall loss of certain condensable material from the gas phase dominates over particle loss processes (Saathoff et al., 2009).

For a further discussion it is useful to estimate the gasphase fraction of pinic and pinonic acids under the experimental conditions (see Table 1 for values and constants). This can be done by using the accepted models of gas/particle partitioning (Donahue et al., 2006; Hoffmann et al., 1997; Odum et al., 1996) and assuming a mass equivalent saturation concentration $\left(C^{*}\right.$ at $\left.300 \mathrm{~K}\right)$ for pinic acid of $10^{1} \mu \mathrm{g} \mathrm{m}{ }^{-3}$ and for pinonic acid of $10^{3} \mu \mathrm{g} \mathrm{m}^{-3}$ as well as an organic mass load of $16 \mu \mathrm{g} \mathrm{m}^{-3}$, consistent with the SIMPOL structureactivity relation (Pankow and Asher, 2008). The resulting calculated gas-phase fractions of pinic and pinonic acid at $283 \mathrm{~K}$ is about $14 \%$ for pinic acid and $98 \%$ for pinonic acid. This estimation shows why especially pinonic acid particles rapidly evaporate shortly after being introduced into the chamber. This conclusion is consistent with the missing increase of particle mass concentration. The only significant increase of APCI(-)/MS signal intensity $m / z, 183$ was observed during active addition of pinonic acid aerosol; the signal vanished immediately after addition ceased. This effect may be attributed to a small fraction of particle phase pinonic acid reaching the inlet of the APCI/MS(-) before evaporation and/or mixing with the full AIDA volume. Due to a smaller gas phase fraction of pinic acid, wall losses of the substance are less pronounced. Finally, if we consider MBTCA as least volatile compound in the system
( $C^{*}$ of $10^{-3} \mu \mathrm{g} \mathrm{m}^{-3}$ for MBTCA), the connection between gas/particle-partitioning and wall loss by uptake of gaseous compounds can be further stressed. The gas phase fraction of MBTCA calculates to about $0.002 \%$. As expected, no significant decrease in the APCI(-)/MS mass trace $m / z 203$ (Fig. 2) can be observed (06:15 h experiment time).

It is worthwhile to estimate the gas-phase concentration of pinonic and pinic acid during the experiments. In contrast to the period when pinic acid aerosol was added, when the gas-phase concentration of pinic acid can be assessed from the measured aerosol mass and the $C^{*}$-value, this procedure is more difficult for the periods when only pinonic acid aerosol was added, due to the lack of a measurable particle phase. However, a simple calculation based on the estimated input rate of pinonic acid into the chamber of $3.3 \times 10^{-2} \quad \mu^{-3} \mathrm{~m}^{-3} \mathrm{~s}^{-1}$ and the estimated wall loss from the gas phase (see above) allows an estimation of the pinonic acid gas-phase concentration. Based on these calculations a maximum gas-phase concentration of about $40 \mu \mathrm{g} \mathrm{m}^{-3}$ was estimated (well below saturation).

\subsection{OH-initiated aging of pinic and pinonic acid}

As already discussed, the major fraction of pinonic acid is present in the gas phase at $283 \mathrm{~K}$ and consequently the addition of pinonic acid aerosol into the chamber in the absence of OH-radicals (Fig. 2, 03:15-03:40 h experiment time) did not lead to a significant increase in particle mass concentration. In contrast, when pinonic acid was added in the presence of OH-radicals (Fig. 2, 04:40-05:20 h experiment time) the particle mass concentration increased by about $3 \mu \mathrm{g} \mathrm{m}^{-3}$. Obviously pinonic acid is oxidized by $\mathrm{OH}-$ radicals, which leads to the formation of lower-volatility reaction products. At the same time, the APCI/MS showed an increase in the mass trace $m / z 203$ (the deprotonated ((M$\mathrm{H}^{-}$) of MBTCA) (see Fig. 2). Also the extracts of the filters taken during that time and analyzed by LC/MS showed the presence of MBTCA, which could be verified by the use of an authentic standard compound (comparison of retention time and mass spectrum). Therefore, MBTCA could be unambiguously identified as an oxidation product during the 
$\mathrm{OH}$-radical initiated processing of pinonic acid. Along with the generation of MBTCA, a simultaneous increase in signal intensity of the mass traces of $m / z$ 199, $m / z 213, m / z$ 215; $\mathrm{m} / z 229$ and $\mathrm{m} / z 231$ was observed (Fig. 3). These signals are likely to originate from side products of the MBTCA generation process. An identification of these products by LC/MS analysis was not possible, essentially due to the lack of authentic standard compounds. A more detailed discussion about the potential nature of these compounds can be found in Sect. 3.3.

Pure pinic acid aerosol was also exposed to $\mathrm{OH}$ radicals (Fig. 2, 02:00-03:00 $\mathrm{h}$ experiment time). The mass trace of pinic acid $(\mathrm{m} / \mathrm{z} 185)$ showed a slightly steeper downward slope when $\mathrm{OH}$ was present in the gas phase, indicating that pinic acid is also consumed by the $\mathrm{OH}$ reaction. There is no way to determine whether the pinic acid was consumed heterogeneously, in the gas phase, or via some combination of the two. However, the signs of reaction are much less dramatic than for pinonic acid. Specifically, the particle mass concentration (Fig. 2, black dots) shows no additional particle-phase material being produced, and no evidence for the production of MBTCA $(m / z, 203)$ can be found during the oxidation of pinic acid. Nevertheless, a slightly different temporal behavior of other ion mass traces in the APCI()/MS could be observed. During the pinic acid oxidation (02:00-03:00 h experiment time) the mass traces of $m / z 213$ $\mathrm{m} / \mathrm{z} 229, \mathrm{~m} / \mathrm{z} 231$ show a small increase in intensity (see Fig. 3) indicating the formation of other oxidation products than MBTCA. Unfortunately nothing can be said about their chemical identity. One explanation that only minor changes were observed might be the fact that a much lower fraction of pinic acid resides in the gas phase and hence much smaller amounts react, forming smaller amounts of products, or that any diffusion limited heterogeneous reaction is simply slower than the homogeneous gas-phase oxidation of pinonic acid [Lambe EST 2009]. However, due to the different chemical nature of pinic acid certainly also other products will be formed than in the case of pinonic acid oxidation and these products might be characterized by a higher degree of fragmentation and by a higher volatility.

The observations just described above already suggest that gas-phase processing of the two SOA compounds is the dominant process, since pinonic acid, which mainly resides in the gas phase, clearly produces a significant amount of condensable material, whereas pinic acid, which has a much lower volatility and mainly resides in the condensed phase, shows only minor indications for an ongoing formation of condensable material. This conclusion is supported by measurements of the MBTCA concentrations during $\alpha$-pinene SOA aging experiments at different temperatures, which is shown in Fig. 4. The figure summarizes a set of aging experiments, which were performed at four different temperatures $(253 \mathrm{~K}, 273 \mathrm{~K}, 293 \mathrm{~K}$ and $313 \mathrm{~K})$. The main difference to the experiments described above is that instead of oxidizing a single SOA compound (i.e. pinonic or pinic

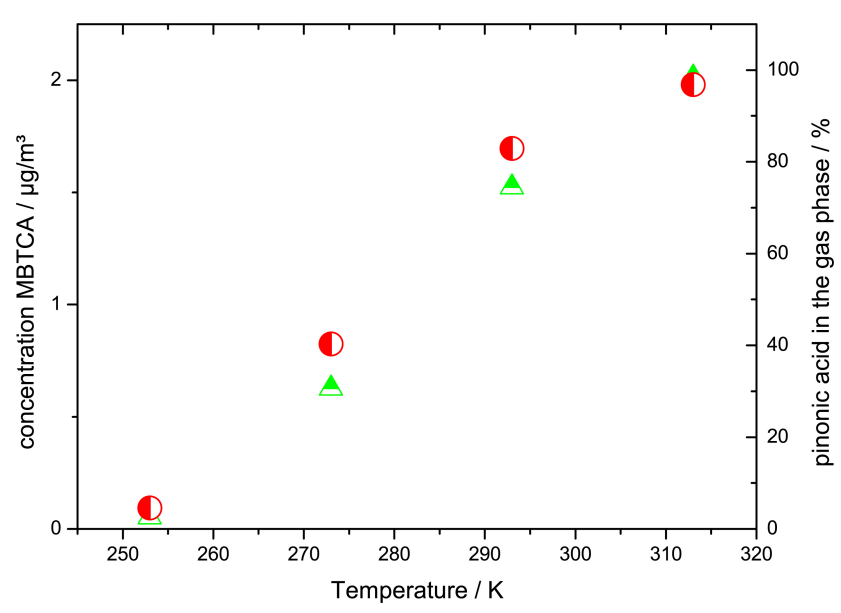

Fig. 4. Concentration of MBTCA (triangle) derived from $\alpha$-pinene SOA aging at different temperatures; magnitude of gas phase fraction of pinonic acid (circles) at different temperatures.

acid), $\alpha$-pinene SOA was processed in the presence of $\mathrm{OH}$ radicals (from reaction of TME with ozone). SOA was produced by ozonolysis of $\alpha$-pinene. For all temperatures an individual initial $\alpha$-pinene concentration was chosen to keep the final aerosol mass concentration of $\alpha$-pinene SOA roughly constant at about $20 \mu \mathrm{g} \mathrm{m}^{-3}$. Figure 4 shows the results of the LC/ESI-MS quantification of the MBTCA concentrations (triangles) at the different temperatures. The measured MBTCA concentrations show a clear temperaturedependence with low MBTCA concentrations at lower temperatures and high MBTCA concentrations at higher temperatures. Since no direct measurement of the gas-phase concentration of pinonic acid was possible, the theoretically predicted gas-phase fraction of pinonic acid at the different temperatures is also shown in Fig. 4 (circles). These values were estimated based on the expected temperature dependence of the effective saturation concentration of pinonic acid and the available aerosol mass concentration. As can be seen in the figure, the measured MBTCA concentration increases with the fraction of pinonic acid in the gas phase, strongly indicating that the generation of MBTCA is a gas-phase process. A more detailed discussion also including the MBTCA yields normalized to the initial $\alpha$-pinene concentration is presented in the Supplement.

\subsection{Formation mechanism}

The mass spectrometric investigations unambiguously identified MBTCA as a product of the hydroxyl radical initiated oxidation of pinonic acid in the gas phase. It is therefore necessary to explore possible chemical pathways leading from the ketocarboxylic acid to the branched tricarboxylic acid. Consequently, the following discussion focuses on potential pathways to form MBTCA from pinonic acid. Thus, only those pathways are discussed that can lead 
Table 2. Site specific and total rate coefficients for hydrogen abstraction from pinonic acid by $\mathrm{OH}$ radicals.

\begin{tabular}{lll}
\hline H-abstraction site & $k / 10^{-12} \mathrm{~cm}^{3} \mathrm{molec}^{-1} \mathrm{~s}^{-1}$ & $\%$ \\
\hline $\mathrm{C}-2$ & $4.1^{\mathrm{a}}$ & 36 \\
$\mathrm{C}-3$ & $3.0^{\mathrm{a}}$ & 27 \\
$\mathrm{C}-5$ & $2.0^{\mathrm{a}}$ & 18 \\
$\mathrm{C}-9 / 10$ & $0.8^{\mathrm{a}}$ & 7.1 \\
$\mathrm{C}-4$ & $0.4^{\mathrm{a}}$ & 3.5 \\
$\mathrm{C}-7$ & $0.1^{\mathrm{a}}$ & 0.8 \\
$\mathrm{O}$ & $0.85^{\mathrm{b}}$ & 7.5 \\
\hline Total & 11.25 & \\
\hline
\end{tabular}

According to calculations by Vereecken et al. (2002) $)^{\mathrm{a}}$ and ${ }^{\mathrm{b}}$ Khamaganov et al. (2006).

to MBTCA formation. An additional puzzle is the speed of the MBTCA formation; in all cases (e.g. Fig. 2) the tricarboxylic acid signal rises almost immediately after the onset of pinonic acid oxidation. The MBTCA thus behaves like a first-generation oxidation product, despite having two additional acid moieties. It would thus appear that the initial $\mathrm{OH}-$ radical attack on the pinonic acid is the rate-limiting step to MBTCA formation.

The oxidation of pinonic acid by $\mathrm{OH}$ radicals is initiated by hydrogen atom abstraction, which can take place at different sites of the molecule (see Fig. 1b for labeling), resulting in the formation of different alkyl radicals. The sitespecific rate coefficients depend on the interactions of individual carbon centers with the $\mathrm{OH}$ radical, but $\mathrm{H}$-atom abstraction will occur over the entire structure, as discussed below. For the formation of MBTCA starting from pinic acid, one must accomplish three things: the acetyl group (carbons 6 and 7) must be eliminated; the cyclobutane ring must open between carbons 4 and 5; and finally carbons 4 and 5 must be functionalized as carboxyl groups. This is a formidable synthetic challenge, made more so because the MBTCA appears very rapidly after $\mathrm{OH}$ addition, under low-NOx conditions and low (36\%) RH. However, there are strong indications from ambient aerosol mass spectrometry that aged organic aerosol (LV-OOA) in the atmosphere contains substantial carboxyl functionality (Jimenez2009). MBTCA is in many ways an excellent surrogate for LV-OOA, with similar volatility and O:C. Consequently, elucidating its gas-phase formation mechanism is likely to lead to substantial insight into broader chemical pathways in the atmosphere.

Partial rate coefficients for pinonic acid and related compounds (Table 2) have been calculated by Vereecken and Peeters (2002) and Khamaganov et al. (2006). Based on this work, the main site of hydrogen abstraction is carbonatom C-2 (36\%), followed by C-3 (27\%), C-5 (18\%), carboxylic acid O (7.5\%), C-9/10 (7.1\%), C-4 (3.5\%), C-7 $(0.8 \%)$. The values given here are estimates based on the partial rate coefficients and therefore subject to considerable uncertainty. However, the position of the initial hydrogen atom abstraction substantially governs the subsequent oxidation processes. Hence, the products of the oxidation process are strongly influenced by the initial hydrogen atom abstraction site. Beside the location of the initial $\mathrm{H}$-abstraction, further reaction pathways are mainly controlled by the fate of the intermediate alkoxy radicals RO. In general, alkoxy radicals are formed after alkyl radicals add oxygen, forming the corresponding alkylperoxy radicals $\mathrm{RO}_{2}$. In the presence of nitrogen oxides alkylperoxy radicals predominantly react with NO to from alkoxy radicals and alkylnitrates. Since nitrate formation is generally considered to be a minor channel and is very unlikely to lead to the formation of MBTCA, this pathway is neglected in the subsequent discussion. Alternatively, under low $\mathrm{NO}_{\mathrm{x}}$ conditions (as in the experiments described above), $\mathrm{RO}_{2}$ can react with $\mathrm{HO}_{2}$ or undergo self and cross reactions, the latter also leading to alkoxy radicals $\mathrm{RO}$ (Kroll and Seinfeld, 2008). Reaction with $\mathrm{HO}_{2}$ forms hydroperoxides, which may react further, for example in the particle phase to form peroxyhemiacetals (Tobias and Ziemann, 2000). Although we cannot completely rule out that hydroperoxides are also forming MBTCA as a further reaction product, also this pathway is neglected in the further discussion.

The alkoxy radical itself can undergo three possible reactions. (a) Dissociation into an alkyl radical and a carbonyl compound. (b) Isomerization to an alkyl radical and a hydroxyl function, via a hydrogen rearrangement, especially $1,5 \mathrm{H}$-shift. (c) Reaction with oxygen forming carbonyl components and $\mathrm{HO}_{2}$. The rates of these three possible reactions strongly depend on the molecular structure of the individual alkoxy radical and vary from radical to radical. For the present mechanism, the individual calculation of the branching ratio of each alkoxy radical reaction is based on rate constants for alkoxy radical reactions recommended by Atkinson (2007) and Kroll and Seinfeld (2008)(Table 3) (Atkinson, 2007; Kroll and Seinfeld, 2008). As already mentioned above, only those pathways are discussed in detail, which can lead to the formation of MBTCA.

Clearly one of the most important steps governing the subsequent reaction pathway is the site of the initial $\mathrm{H}$ abstraction. Consequently, it is obvious to discuss which $\mathrm{H}$-atom abstraction initiates a reaction sequence that subsequently can lead to the formation of MBTCA and which not. For each possible initial $\mathrm{H}$-atom abstraction site, Fig. 5 outlines the first steps in the reaction chain. As shown in Table 2 an $\mathrm{H}$-atom abstraction from $\mathrm{C}$-atom $\mathrm{C}-2$ and $\mathrm{C}-3$ is in fact most likely. However, the pathways initiated by these abstractions cannot lead to the formation of MBTCA. The same is the true for an $\mathrm{H}$-abstraction at $\mathrm{C}-9 / 10$. At these sites the initial $\mathrm{OH}$ attack will lead to product structures in which certain hydrogen atoms are already abstracted that are structural elements of MBTCA. However, when the initial $\mathrm{H}$-atom abstraction is taking place at C-atoms C-4, C-5 and C-7 an oxidation chain to form MBTCA is possible. These 


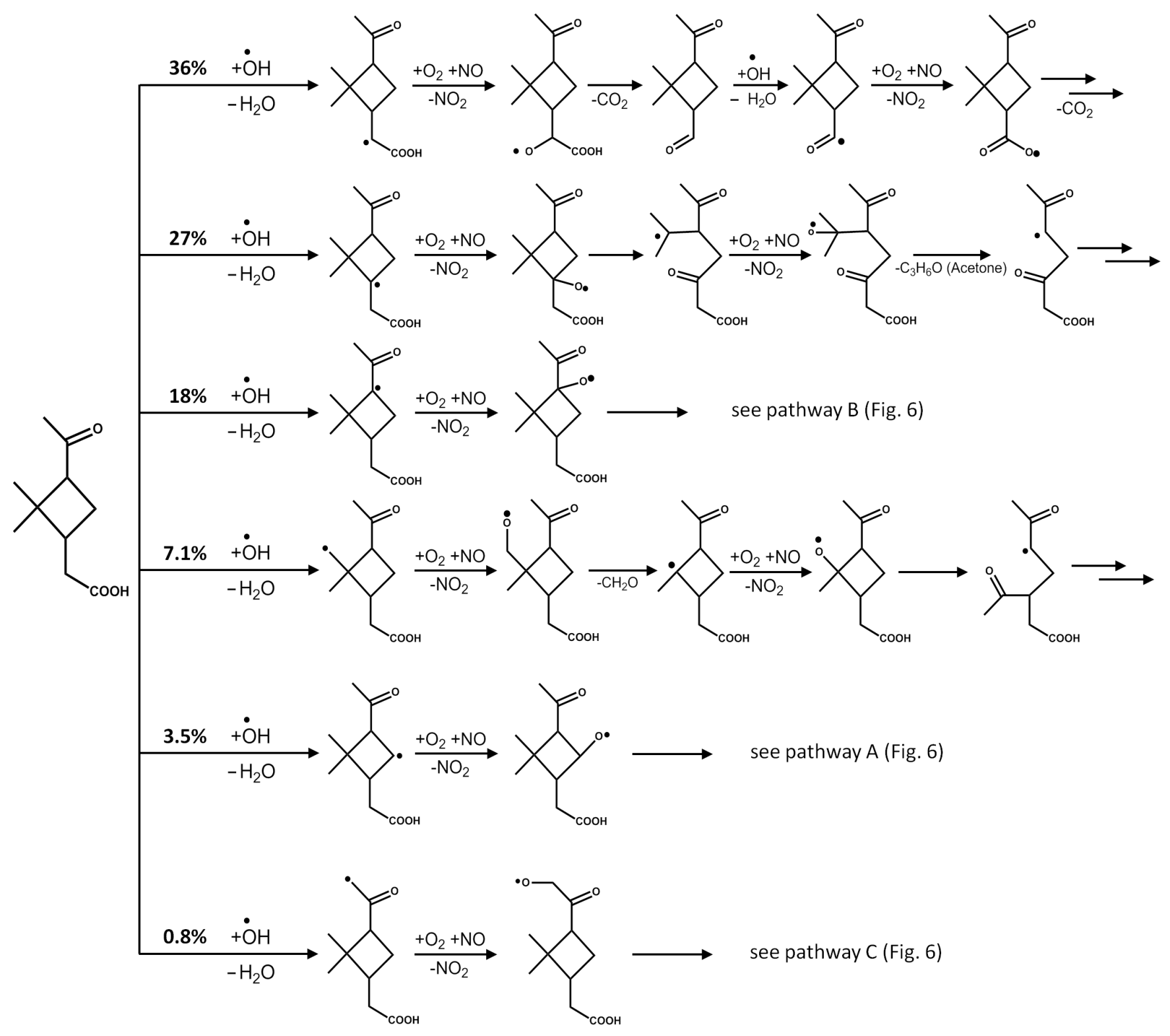

Fig. 5. Initial reaction steps of hydroxyl radical oxidation of pinonic acid by $\mathrm{OH}$ radicals.

pathways are discussed in detail in the following paragraphs as well as in Fig. 6.

(a) $\mathrm{H}$-atom abstraction from the C-4 carbon atom (pathway A). Vereecken and Peeters (2002) estimated that $\mathrm{H}$-atom abstraction by $\mathrm{OH}$ from pinonic acid should take place from the C-4-atom at a fraction of $3.5 \%$. The formed alkyl radical R31 will subsequently react with oxygen and NO to the alkoxy radical R32. This radical will mainly decompose by an opening the cyclobutane ring, resulting in two isomeric alkyl radicals. In alkyl radical R33 the radical is located at the $\mathrm{C}-5$-atom, in the isomeric structure the radical is located at the C-3 carbon atom (not shown in Fig. 6). Both isomers are predicted to form with a fraction of $47 \%$. The reaction can continue with alkyl radical R33 forming another alkoxy radical (R34) by adding oxygen and reacting with $\mathrm{NO}\left(\right.$ or $\left.\mathrm{RO}_{2}\right)$. $\mathrm{R} 34$ can undergo a 1,5 $\mathrm{H}$-shift, resulting in a hydroxy group and an acyl radical (R35) located at the $\mathrm{C}_{4}$-carbon atom. Fantechi et al. suggest this isomerization step to be quasibarrierless therefore very fast $\left(k \sim 1 \times 10^{11}-1 \times 10^{12} \mathrm{~s}^{-1}\right)$ and efficient (Fantechi et al., 2002). However, more recent findings (Vereecken and Peeters, 2010) suggest that H-migration of an aldehyde- $\mathrm{H}$ might have a higher barrier than obtained in older studies. In this case the formation of a $\mathrm{C}_{8}$ dialdehydecarboxylic acid (P25; see pathway B) would be the dominant reaction pathway. Otherwise, the product of the $\mathrm{H}$-migration, the acyl radical $\mathrm{R} 35$ can undergo the typical $\mathrm{O}_{2} / \mathrm{NO}$ reaction 


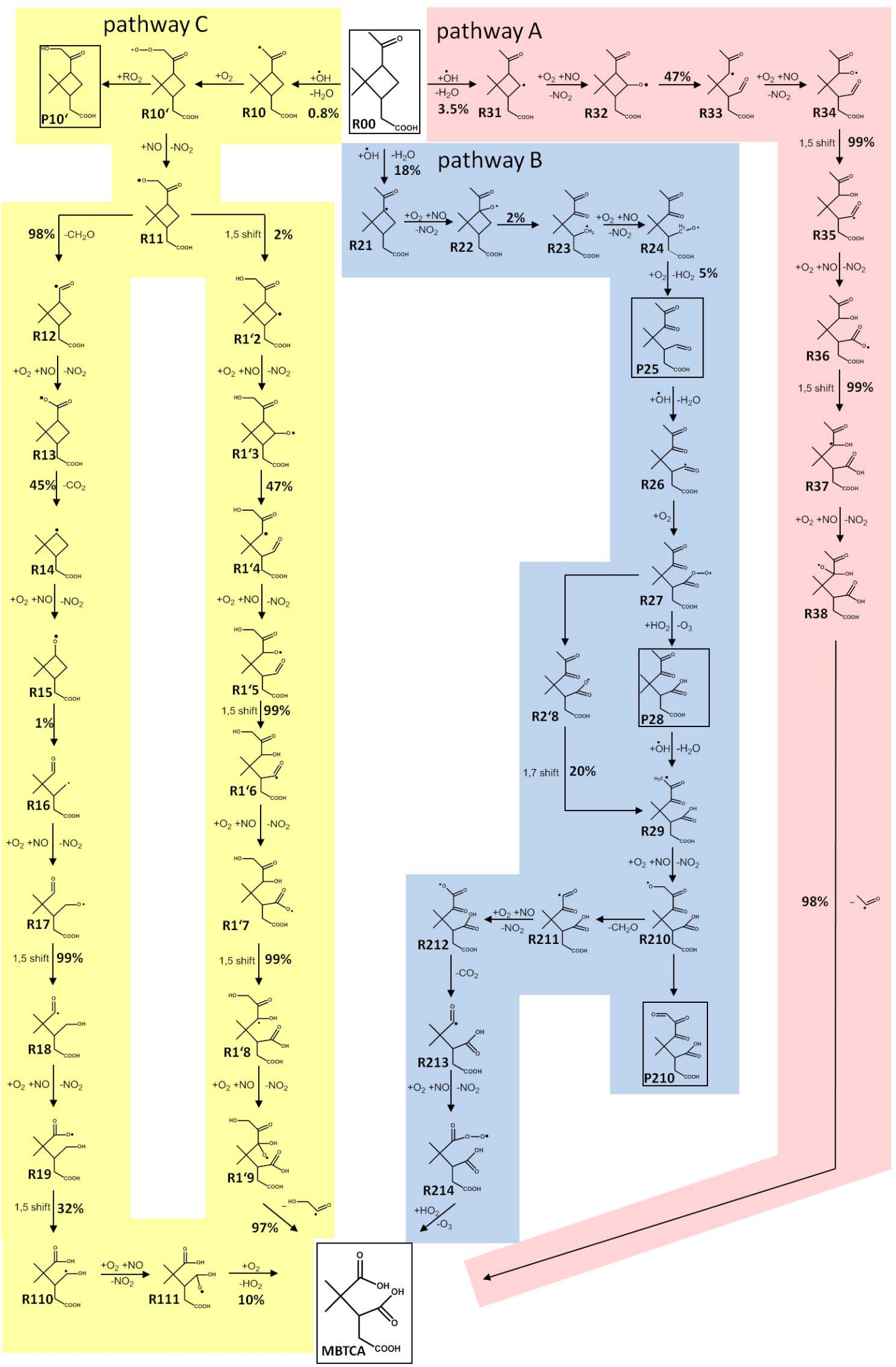

Fig. 6. Proposed formation mechanisms of MBTCA by oxidation of pinonic acid. 
Table 3. Rates of alkoxy radical reactions as presented by Kroll and Seinfeld (2008), based upon recommendations by Atkinson (2007).

\begin{tabular}{ll}
\hline Reaction type & Rate constant at $298 \mathrm{~K}\left(\mathrm{~s}^{-1}\right)$ \\
\hline $\begin{array}{l}\text { Dissociation } \\
\text { Leaving radical }\end{array}$ \\
\hline $\mathrm{CH}_{3}$ & $1.5 \times 10^{2}$ \\
$\mathrm{CH}_{2} \mathrm{R}$ & $4.7 \times 10^{4}$ \\
$\mathrm{CHR}_{2}$ & $4.2 \times 10^{5}$ \\
$\mathrm{CR}_{3}$ & $2.7 \times 10^{6}$ \\
$\mathrm{CH}_{2} \mathrm{OH}$ & $4.5 \times 10^{6}$ \\
$\mathrm{CHROH}$ & $6.7 \times 10^{7}$ \\
$\mathrm{CR}$ & $1.3 \times 10^{8}$ \\
$\mathrm{C}(\mathrm{O}) \mathrm{H}$ & $2.0 \times 10^{4}$ \\
$\mathrm{C}(\mathrm{O}) \mathrm{R}$ & $9.5 \times 10^{7}$ \\
\hline
\end{tabular}

\begin{tabular}{ll}
\hline $\begin{array}{l}\text { Isomerization } \\
\text { Carbon from which } \mathrm{H} \\
\text { atom is abstracted }\end{array}$ \\
\hline$-\mathrm{CH}_{3}$ & $2.5 \times 10^{5}$ \\
$-\mathrm{CH}_{2} \mathrm{R}$ & $2.5 \times 10^{6}$ \\
$-\mathrm{CHR}_{2}$ & $8.5 \times 10^{6}$ \\
$-\mathrm{CH}_{2} \mathrm{OH}^{\mathrm{c}}$ & $1.0 \times 10^{7}$ \\
$-\mathrm{CHROH}^{\mathrm{c}}$ & $3.4 \times 10^{7}$ \\
\hline Reaction with $\mathrm{O}_{2}^{\mathrm{d}}$ & $4.7 \times 10^{4}$ \\
\hline
\end{tabular}

${ }^{\text {a }}$ To obtain these values $\Delta \mathrm{H}_{\text {dissoc }}$ is assumed to be $7 \mathrm{kcal} \mathrm{mol}^{-1}$ Substantially higher accuracy can be obtained by using actual $\Delta \mathrm{H}_{\text {dissoc }}$ values from individual reactions, Atkinson (2007). ${ }^{b}$ Multiply rate constants by 1.3 for each adjacent non-methyl carbon, or 3.5 if adjacent carbon has hydroxyl group. ${ }^{\mathrm{c}}$ Hydrogen abstraction from carbon atom only ${ }^{\mathrm{d}}$ At 760 Torr air.

sequence to form the acyloxy radical R36. Due to the hydroxy group at carbon atom C-5, R36 is very likely to undergo isomerization with a high yield resulting in alkyl radical R37, which again can add $\mathrm{O}_{2}$ and react with NO. The resulting alkoxy radical $\mathrm{R} 38$ is likely to decompose into a $\mathrm{C}_{2} \mathrm{H}_{3} \mathrm{O}$ radical and MBTCA. Another very important competing reaction which has to be taken into account is the decarboxylation of R36 (Vereecken and Peeters, 2009). Compared to the H-migration the decarboxylation can be expected to possess a much more favorable entropic factor.

The percentage numbers in Fig. 6 show an estimation of the branching ratios of the individual pathways. As mentioned above, these numbers are mainly based on the estimation of the relative rates of the possible alkoxy radical reactions and are certainly just a rough estimation of the potential contribution of the individual pathways. However, if all these numbers are used for a first assessment of the relative product yield, the MBTCA yield from this pathway is estimated to be about $1.6 \%$. If the formation of P25 and its further reactions following pathway B (see next paragraph) is included the estimated yield would drop to quite low values (about $0.031 \%$ ). If we consider the decarboxylation of R36 to be the favorite pathway the total yield would decrease to zero. In that case pathway A is not applicable.

(b) H-atom abstraction from the C-5 carbon atom (pathway B). According to the rate constant of $2.0 \times 10^{-12} \mathrm{~cm}^{3} \mathrm{molec}^{-1} \mathrm{~s}^{-1}$ (Table 2) about $18 \%$ of the $\mathrm{H}$ abstractions by $\mathrm{OH}$ are expected to occur at the $\mathrm{C}-5$ carbon atom. The resulting alkyl radical (R21) will add oxygen, after which the alkylperoxy radical will form the alkoxy radical R22. The fate of the alkoxy radical R22, however, is the key step in this part of the mechanism. R22 will solely undergo dissociation, which will result in an opening of the cyclobutane ring. The opening of cyclobutane rings by decomposition of alkyl radicals has been discussed in detail by Vereecken et al. (2009) and Fantechi et al. (2002). Two ring-opening scenarios are possible. The most likely ( $98 \%$ ) will lead to a tertiary alkyl radical at the C-8 carbon atom and a keto-function at C-5 (structure not shown in the figure). The less likely ring opening ( $2 \%$ ) will lead to R23, introducing a primary alkyl radical at $\mathrm{C}-4$ and a keto-function at $\mathrm{C}-5$. The tertiary alkyl radical will react with oxygen and $\mathrm{NO}$ (if present) to form an alkoxy radical. This radical is likely to decompose into a molecule of acetone and a new alkyl radical that has lost the two characteristic methyl groups of MBTCA (Fantechi et al., 2002; Noziere et al., 1999). The chain to MBTCA continues with the reaction of R23 with oxygen and $\mathrm{NO}$ to form alkoxy radical R24. According to the rate constants (Tab.3), about $5 \%$ of R24 undergo reaction with oxygen to from P25. Actually, evidence of a product with a molecular weight of 214 can be seen in the on-line mass spectra (Fig. 3 on-line APCI(-)/MS mass trace $m / z$ 213). $95 \%$ of R24 undergoes dissociation (elimination of formaldehyde) and isomerization (C-9 and C-10) reactions. The next step in the chain is another $\mathrm{H}$-atom abstraction by $\mathrm{OH}$ from $\mathrm{P} 25$. The abstraction should mainly occur from C-4, to form R26, followed by adding $\mathrm{O}_{2}$. The resulting acylperoxy radical R27 can react with $\mathrm{HO}_{2}$ to form product $\mathrm{P} 28$. Again mass spectrometric evidence is shown in Fig. 3 (Fig. 3 on-line APCI(-)/MS mass trace $m / z$ 231). For the next step an Hatom abstraction from C-7 is needed, forming alkyl radical R29. This radical will react with oxygen and NO to form alkoxy radical R210, which will eliminate formaldehyde exclusively (99\%), forming R211. The fate of R211 is to form acyloxy radical R212 via the addition of oxygen and reaction with NO. R212 will eliminate $\mathrm{CO}_{2}(97 \%)$, to form acyloxy radical $\mathrm{R} 213$, which reacts by the addition of $\mathrm{O}_{2}$ forming the acylperoxy radical R214. R214 finally can react with $\mathrm{HO}_{2}$ to produce MBTCA and ozone (Jenkin et al., 2007; Le Crane et al., 2006) . It is obvious, due to the low percentage of the key step and because of two additional $\mathrm{OH}$ reactions needed, that this pathway is not very likely and MBTCA is not a main product. However, based on the branching percentages an approximate yield of MBTCA can be calculated to be only about $0.01 \%$ via pathway $\mathrm{B}$. 
Table 4. Theoretical Yields of MBTCA formation by oxidation of pinonic acid via different pathways.

\begin{tabular}{lll}
\hline $\begin{array}{l}\text { H-abstraction } \\
\text { site }\end{array}$ & Pathway & Yield \% \\
\hline C-4 & A & 1.6 \\
& $\mathrm{~A} \mathrm{CO}_{2}$ elimination & 0 \\
& $\mathrm{~A}$ branching to P25 & 0.031 \\
$\mathrm{C}-5$ & $\mathrm{~B}$ & 0.0004 \\
$\mathrm{C}-7$ & $\mathrm{C}$ & 0.00014 \\
& $\mathrm{C}$ & 0.011 \\
& Total Range & $0.012 \%-1.6 \%$ \\
\hline
\end{tabular}

(c) H-atom abstraction from the C-7 carbon atom (pathway $\mathrm{C}$ and $\mathrm{C}^{\prime}$ ). $\mathrm{H}$-abstraction by $\mathrm{OH}$ radicals from $\mathrm{C}-7$ carbon atom of pinonic acid has the lowest rate constant (Table 2) and thus is predicted to be a minor reaction channel right from the beginning of the reaction sequence (about $1 \%$ ). Therefore, we abandon a detailed discussion of the possible reaction pathways possibly leading to MBTCA. However, it should be noted that other authors (Kourtchev et al., 2009) consider this pathway to be a relevant pathway in the formation of MBTCA and we refer the reader to the original paper for a more detailed discussion. Nevertheless, for the matter of completeness these pathways are also shown in Fig. 6 and a comprehensive discussion of pathway $\mathrm{C}$ is given in the Supplement.

\subsection{Yield of MBTCA}

All individual yield estimations for each of the MBTCA formation pathway discussed above are summarized in Table 4 . Pathway A clearly turns out to be the most likely one, however, as discussed above the inclusion of alternative pathways would alter this conclusion. Nevertheless, pathway A also has some features consistent with the data. Specifically, it requires only a single $\mathrm{OH}$ attack, and while it does require several $\mathrm{NO} \rightarrow \mathrm{NO}_{2}$ conversions, it is possible that other peroxy radical pathways are active outside of this "canonical" route. The contributions of pathway $\mathrm{B}$ and $\mathrm{C}$ can probably be neglected. Nevertheless, pathway B at least suggests two significant products that actually have been observed in the on-line mass spectra (Fig. $3 \mathrm{~m} / z 213 ; \mathrm{m} / z$ 229). Overall, by evaluating the individual branching ratios of the reaction mechanism as discussed above a range of the theoretical yield for MBTCA between $0.012 \%$ and $1.6 \%$ from pinonic acid oxidation can be estimated. This result clearly shows that MBTCA is not a main product of the $\mathrm{OH}$ initiated oxidation of pinonic acid. However, a closer look especially to pathway A suggests that other SOA compounds, which exhibit a similar constitution as pinonic acid (e.g. pinonaldehyde, hydroxypinonic acid), can also be oxidized to MBTCA by an initial $\mathrm{H}$-atom abstraction from the $\mathrm{C}-4$ carbon atom.
Consequently, the overall yield from for example $\alpha$-pinene oxidation might actually be higher.

In addition to the on-line measurements, an off-line quantification of MBTCA was performed by analyzing filter samples taken during the pinonic acid oxidation experiments by LC/MS. As a result, an average concentration of MBTCA of $0.27 \mu \mathrm{g} \mathrm{m}^{-3}\left( \pm 0.1 \mu \mathrm{g} \mathrm{m}^{-3}\right.$ ) was measured. Considering the calculated average gas phase concentration of pinonic acid during the experiment $\left(40 \mu \mathrm{g} \mathrm{m}^{-3}\right)$ and assuming a complete consumption of PA, an experimental yield of $0.61 \%$ can be determined. This experimental result is within the range of the theoretical predictions, although one has to consider that both experimental and theoretical yield estimations are just rough approximations based on several assumptions. However, it can be concluded that the majority of pinonic acid is degraded to other products than MBTCA. However, in SOA formation a "minor" overall product can nevertheless be important. Here, in the course of the oxidation of pinonic acid, a mass increase of about $3 \mu \mathrm{g} \mathrm{m}^{-3}$ was observed (see Fig.2). This means that MBTCA formation explains at least about $10 \%$ of the newly formed particle phase material. On-line APCI(-)/MS and LC/MSMS experiments revealed other side products, however, due to the lack of authentic standards a quantification and identification was not possible within this study. Therefore, the majority of the particle phase material formed after pinonic acid oxidation remains ambiguous.

\section{Conclusions}

This study confirms 3-methyl-1,2,3-butanetricarboxylic acid (MBTCA) as an important low volatility aging product of the gas-phase oxidation of pinonic acid. MBTCA was observed and characterized by a complementary method of online APCI/MS and filter analysis via liquid chromatographyESI-mass spectrometry. The formation of MBTCA explains about $10 \%$ of the newly formed SOA mass. The experimental yield was determined to be about $0.61 \%$. Several different reaction pathways have been developed and discussed in respect to individual branching ratios and potential relative contribution to MBTCA formation. The formation of MBTCA from pinonic acid oxidation is an important evidence for oxidative aging processes of biogenic SOA occurring in the atmosphere. At this point more work is needed to reveal additional SOA compounds as precursors for MBTCA and establish MBTCA as a multi-precursor aging product.

\section{Supplement related to this article is available online at: http://www.atmos-chem-phys.net/12/1483/2012/ acp-12-1483-2012-supplement.pdf.}

Acknowledgements. We thank the AIDA team at KIT for their effective support during the measurement campaign and the EUROCHAMP-2 project within the EC 7th framework programme for financial support. 
Edited by: F. Keutsch

\section{References}

Atkinson, R.: Rate constants for the atmospheric reactions of alkoxy radicals: An updated estimation method, Atmos. Environ., 41, 8468-8485, 2007.

Bilde, M. and Pandis, S. N.: Evaporation rates and vapor pressures of individual aerosol species formed in the atmospheric oxidation of alpha- and beta-pinene, Environ. Sci. Technol., 35, 33443349, 2001.

de Gouw, J. A., Middlebrook, A. M., Warneke, C., Goldan, P. D., Kuster, W. C., Roberts, J. M., Fehsenfeld, F. C., Worsnop, D. R., Canagaratna, M. R., Pszenny, A. A. P., Keene, W. C., Marchewka, M., Bertman, S. B., and Bates, T. S.: Budget of organic carbon in a polluted atmosphere: Results from the New England Air Quality Study in 2002, J. Geophys. Res.-Atmos., 110, 22 pp., D16305, doi:10.1029/2004JD005623, 2005.

Donahue, N. M., Robinson, A. L., Stanier, C. O., and Pandis, S. N.: Coupled partitioning, dilution, and chemical aging of semivolatile organics, Environ. Sci. Technol., 40, 2635-2643, 2006.

Donahue, N. M., Robinson, A. L., and Pandis, S. N.: Atmospheric organic particulate matter: From smoke to secondary organic aerosol, Atmos. Environ., 43, 94-106, 2009.

Fantechi, G., Vereecken, L., and Peeters, J.: The OH-initiated atmospheric oxidation of pinonaldehyde: Detailed theoretical study and mechanism construction, Phys. Chem. Chem. Phys., 4, 5795-5805, 2002.

Gao, Y. Q., Hall, W. A., and Johnston, M. V.: Molecular Composition of Monoterpene Secondary Organic Aerosol at Low Mass Loading, Environ. Sci. Technol., 44, 7897-7902, 2010.

George, I. J., Vlasenko, A., Slowik, J. G., Broekhuizen, K. and Abbatt, J. P. D.: Heterogeneous oxidation of saturated organic aerosols by hydroxyl radicals: uptake kinetics, condensed-phase products, and particle size change, Atmos. Chem. Phys., 7, 4187-4201, doi:10.5194/acp-7-4187-2007, 2007.

George, I. J., Chang, R. Y. W., Danov, V., Vlasenko, A., and Abbatt, J. P. D.: Modification of cloud condensation nucleus activity of organic aerosols by hydroxyl radical heterogeneous oxidation, Atmos. Environ., 43, 5038-5045, 2009.

Hallquist, M., Wenger, J. C., Baltensperger, U., Rudich, Y., Simpson, D., Claeys, M., Dommen, J., Donahue, N. M., George, C., Goldstein, A. H., Hamilton, J. F., Herrmann, H., Hoffmann, T., Iinuma, Y., Jang, M., Jenkin, M. E., Jimenez, J. L., KiendlerScharr, A., Maenhaut, W., McFiggans, G., Mentel, T. F., Monod, A., Prevot, A. S. H., Seinfeld, J. H., Surratt, J. D., Szmigielski, R. and Wildt, J.: The formation, properties and impact of secondary organic aerosol: current and emerging issues, Atmos. Chem. Phys., 9, 5155-5236, doi:10.5194/acp-9-5155-2009, 2009.

Hatakeyama, S., Izumi, K., Fukuyama, T. and Akimoto, H.: Reactions of Ozone with Alpha-Pinene and Beta-Pinene in Air Yields of Gaseous and Particulate Products, J. Geophys. Res.Atmos., 94, 13013-13024, 1989.

Hatakeyama, S., Akimoto, H., and Washida, N.: Effect of Temperature on the Formation of Photochemical Ozone in a Propene $\mathrm{NO}_{\mathrm{x}}$ Air Irradiation System, Environ. Sci. Technol., 25, 1884-1890, 1991.
Hoffmann, T., Odum, J. R., Bowman, F., Collins, D., Klockow, D., Flagan, R. C., and Seinfeld, J. H.: Formation of organic aerosols from the oxidation of biogenic hydrocarbons, J. Atmos. Chem., 26, 189-222, 1997.

Hoffmann, T., Bandur, R., Marggraf, U., and Linscheid, M.: Molecular composition of organic aerosols formed in the alphapinene/O-3 reaction: Implications for new particle formation processes, J. Geophys. Res.-Atmos., 103, 25569-25578, 1998.

Hoffmann, T., Bandur, R., Hoffmann, S., and Warscheid, B.: Online characterization of gaseous and particulate organic analytes using atmospheric pressure chemical ionization mass spectrometry, Spectroc. Acta Pt. B-Atom. Spectr., 57, 1635-1647, 2002.

Jenkin, M. E., Saunders, S. M., Wagner, V. and Pilling, M. J.: Protocol for the development of the Master Chemical Mechanism, MCM v3 (Part B): tropospheric degradation of aromatic volatile organic compounds, Atmos. Chem. Phys., 3, 181-193, doi:10.5194/acp-3-181-2003, 2003.

Jenkin, M. E., Hurley, M. D. and Wallington, T. J.: Investigation of the radical product channel of the $\mathrm{CH}_{3} \mathrm{C}(\mathrm{O}) \mathrm{O}_{2}+\mathrm{HO}_{2}$ reaction in the gas phase, Phys. Chem. Chem. Phys., 9, 3149-3162, 2007.

Jimenez, J. L., Canagaratna, M. R., Donahue, N. M., Prevot, A. S. H., Zhang, Q., Kroll, J. H., DeCarlo, P. F., Allan, J. D., Coe, H., Ng, N. L., Aiken, A. C., Docherty, K. S., Ulbrich, I. M., Grieshop, A. P., Robinson, A. L., Duplissy, J., Smith, J. D., Wilson, K. R., Lanz, V. A., Hueglin, C., Sun, Y. L., Tian, J., Laaksonen, A., Raatikainen, T., Rautiainen, J., Vaattovaara, P., Ehn, M., Kulmala, M., Tomlinson, J. M., Collins, D. R., Cubison, M. J., Dunlea, E. J., Huffman, J. A., Onasch, T. B., Alfarra, M. R., Williams, P. I., Bower, K., Kondo, Y., Schneider, J., Drewnick, F., Borrmann, S., Weimer, S., Demerjian, K., Salcedo, D., Cottrell, L., Griffin, R., Takami, A., Miyoshi, T., Hatakeyama, S., Shimono, A., Sun, J. Y., Zhang, Y. M., Dzepina, K., Kimmel, J. R., Sueper, D., Jayne, J. T., Herndon, S. C., Trimborn, A. M., Williams, L. R., Wood, E. C., Middlebrook, A. M., Kolb, C. E., Baltensperger, U., and Worsnop, D. R.: Evolution of Organic Aerosols in the Atmosphere, Science, 326, 1525-1529, 2009.

Kalberer, M., Paulsen, D., Sax, M., Steinbacher, M., Dommen, J., Prevot, A. S. H., Fisseha, R., Weingartner, E., Frankevich, V., Zenobi, R., and Baltensperger, U.: Identification of polymers as major components of atmospheric organic aerosols, Science, 303, 1659-1662, 2004.

Kanakidou, M., Seinfeld, J. H., Pandis, S. N., Barnes, I., Dentener, F. J., Facchini, M. C., Van Dingenen, R., Ervens, B., Nenes, A., Nielsen, C. J., Swietlicki, E., Putaud, J. P., Balkanski, Y., Fuzzi, S., Horth, J., Moortgat, G. K., Winterhalter, R., Myhre, C. E. L., Tsigaridis, K., Vignati, E., Stephanou, E. G. and Wilson, J.: Organic aerosol and global climate modelling: a review, Atmos. Chem. Phys., 5, 1053-1123, doi:10.5194/acp-5-1053-2005, 2005.

Khamaganov, V. G., Bui, V. X., Carl, S. A., and Peeters, J.: Absolute rate coefficient of the $\mathrm{OH}+\mathrm{CH}_{3} \mathrm{C}(\mathrm{O}) \mathrm{OH}$ reaction at $T=287-$ $802 \mathrm{~K}$. The two faces of pre-reactive H-bonding, J. Phys. Chem. A, 110, 12852-12859, 2006.

Kiendler-Scharr, A., Wildt, J., Dal Maso, M., Hohaus, T., Kleist, E., Mentel, T. F., Tillmann, R., Uerlings, R., Schurr, U. and Wahner, A.: New particle formation in forests inhibited by isoprene emissions, Nature, 461, 381-384, 2009.

Kourtchev, I., Copolovici, L., Claeys, M., and Maenhaut, W.: Characterization of Atmospheric Aerosols at a Forested Site in Cen- 
tral Europe, Environ. Sci. Technol., 43, 4665-4671, 2009.

Krc, J.: D1-Pinic Acid-I, Analyt. Chem., 25, 1420-1421, 1953.

Kroll, J. H. and Seinfeld, J. H.: Chemistry of secondary organic aerosol: Formation and evolution of low-volatility organics in the atmosphere, Atmos. Environ., 42, 3593-3624, 2008.

Kroll, J. H., Chan, A. W. H., Ng, N. L., Flagan, R. C., and Seinfeld, J. H.: Reactions of semivolatile organics and their effects on secondary organic aerosol formation, Environ. Sci. Technol., 41, 3545-3550, 2007.

Kroll, J. H., Smith, J. D., Che, D. L., Kessler, S. H., Worsnop, D. R., and Wilson, K. R.: Measurement of fragmentation and functionalization pathways in the heterogeneous oxidation of oxidized organic aerosol, Phys. Chem. Chem. Phys., 11, 8005-8014, 2009.

Kubatova, A., Vermeylen, R., Claeys, M., Cafmeyer, J., Maenhaut, W., Roberts, G., and Artaxo, P.: Carbonaceous aerosol characterization in the Amazon basin, Brazil: novel dicarboxylic acids and related compounds, Atmos. Environ., 34, 5037-5051, 2000.

Kubatova, A., Vermeylen, R., Claeys, M., Cafmeyer, J., and Maenhaut, W.: Organic compounds in urban aerosols from Gent, Belgium: Characterization, sources, and seasonal differences, J. Geophys. Res.-Atmos., 107, 8343, doi:10.1029/2001JD000556, 2002.

Le Crane, J. P., Rayez, M. T., Rayez, J. C., and Villenave, E.: A reinvestigation of the kinetics and the mechanism of the $\mathrm{CH} 3 \mathrm{C}(\mathrm{O}) \mathrm{O}-$ $2+\mathrm{HO} 2$ reaction using both experimental and theoretical approaches, Phys. Chem. Chem. Phys., 8, 2163-2171, 2006.

Miracolo, M. A., Presto, A. A., Lambe, A. T., Hennigan, C. J., Donahue, N. M., Kroll, J. H., Worsnop, D. R., and Robinson, A. L.: Photo-Oxidation of Low-Volatility Organics Found in Motor Vehicle Emissions: Production and Chemical Evolution of Organic Aerosol Mass, Environ. Sci. Technol., 44, 1638-1643, 2010.

Molina, M. J., Ivanov, A. V., Trakhtenberg, S., and Molina, L. T.: Atmospheric evolution of organic aerosol, Geophys. Res. Lett., 31, 5 pp., L22104, doi:10.1029/2004GL02091, 2004.

Müller, L., Reinnig, M. C., Warnke, J., and Hoffmann, T.: Unambiguous identification of esters as oligomers in secondary organic aerosol formed from cyclohexene and cyclohexene/alphapinene ozonolysis, Atmos. Chem. Phys., 8, 1423-1433, doi:10.5194/acp-8-1423-2008, 2008.

Müller, L., Reinnig, M. C., Hayen, H., and Hoffmann, T.: Characterization of oligomeric compounds in secondary organic aerosol using liquid chromatography coupled to electrospray ionization Fourier transform ion cyclotron resonance mass spectrometry, Rapid Comm. Mass Spectrom., 23, 971-979, 2009.

Naumann, K. H.: COSIMA - a computer program simulating the dynamics of fractal aerosols, J. Aerosol Sci., 34, 1371-1397, 2003.

Nel, A.: Air pollution-related illness: Effects of particles, Science, 308, 804-806, 2005.

Noziere, B., Barnes, I., and Becker, K. H.: Product study and mechanisms of the reactions of alpha-pinene and of pinonaldehyde with OH radicals, J. Geophys. Res.-Atmos., 104, 23645-23656, 1999.

Odum, J. R., Hoffmann, T., Bowman, F., Collins, D., Flagan, R. C., and Seinfeld, J. H.: Gas/particle partitioning and secondary organic aerosol yields, Environ. Sci. Technol., 30, 2580-2585, 1996.

Pankow, J. F. and Asher, W. E.: SIMPOL.1: a simple group contribution method for predicting vapor pressures and en- thalpies of vaporization of multifunctional organic compounds, Atmos. Chem. Phys., 8, 2773-2796, doi:10.5194/acp-8-27732008, 2008.

Reinnig, M. C., Warnke, J. and Hoffmann, T.: Identification of organic hydroperoxides and hydroperoxy acids in secondary organic aerosol formed during the ozonolysis of different monoterpenes and sesquiterpenes by on-line analysis using atmospheric pressure chemical ionization ion trap mass spectrometry, Rapid Comm. Mass Spectrom., 23, 1735-1741, 2009.

Robinson, A. L., Donahue, N. M., Shrivastava, M. K., Weitkamp, E. A., Sage, A. M., Grieshop, A. P., Lane, T. E., Pierce, J. R., and Pandis, S. N.: Rethinking organic aerosols: Semivolatile emissions and photochemical aging, Science, 315, 1259-1262, 2007.

Rudich, Y., Donahue, N. M., and Mentel, T. F.: Aging of organic aerosol: Bridging the gap between laboratory and field studies, Ann. Rev. Phys. Chem., 58, 321-352, 2007.

Saathoff, H., Mohler, O., Schurath, U., Kamm, S., Dippel, B., and Mihelcic, D.: The AIDA soot aerosol characterisation campaign 1999, J. Aerosol Sci., 34, 1277-1296, 2003.

Saathoff, H., Naumann, K. H., Mohler, O., Jonsson, A. M., Hallquist, M., Kiendler-Scharr, A., Mentel, T. F., Tillmann, R., and Schurath, U.: Temperature dependence of yields of secondary organic aerosols from the ozonolysis of alpha-pinene and limonene, Atmos. Chem. Phys., 9, 1551-1577, doi:10.5194/acp9-1551-2009, 2009.

Saunders, S. M., Jenkin, M. E., Derwent, R. G., and Pilling, M. J.: Protocol for the development of the Master Chemical Mechanism, MCM v3 (Part A): tropospheric degradation of nonaromatic volatile organic compounds, Atmos. Chem. Phys., 3, 161-180, doi:10.5194/acp-3-161-2003, 2003.

Shilling, J. E., King, S. M., Mochida, M., and Martin, S. T.: Mass spectral evidence that small changes in composition caused by oxidative aging processes alter aerosol CCN properties, J. Phys. Chem. A, 111, 3358-3368, 2007.

Shrivastava, M. K., Lipsky, E. M., Stanier, C. O., and Robinson, A. L.: Modeling semivolatile organic aerosol mass emissions from combustion systems, Environ. Sci. Technol., 40, 26712677, 2006.

Szmigielski, R., Surratt, J. D., Gomez-Gonzalez, Y., Van der Veken, P., Kourtchev, I., Vermeylen, R., Blockhuys, F., Jaoui, M., Kleindienst, T. E., Lewandowski, M., Offenberg, J. H., Edney, E. O., Seinfeld, J. H., Maenhaut, W., and Claeys, M.: 3-methyl-1,2,3butanetricarboxylic acid: An atmospheric tracer for terpene secondary organic aerosol, Geophys. Res. Lett., 34, 6 pp., L24811, doi:10.1029/2007GL03133, 2007.

Vanderhoff, P. A., Thompson, H. W., and Lalancette, R. A.: Structure of (+/-)-Cis-Pinonic Acid, Acta Crystallogr. C, 42, 1766$1769,1986$.

Vereecken, L. and Peeters, J.: Enhanced H-atom abstraction from pinonaldehyde, pinonic acid, pinic acid, and related compounds: theoretical study of C-H bond strengths, Phys. Chem. Chem. Phys., 4, 467-472, 2002.

Vereecken, L. and Peeters, J.: Decomposition of substituted alkoxy radicals-part I: a generalized structure-activity relationship for reaction barrier heights, Phys. Chem. Chem. Phys., 11, 90629074, 2009.

Vereecken, L. and Peeters, J.: A structure-activity relationship for the rate coefficient of H-migration in substituted alkoxy radicals, Phys. Chem. Chem. Phys., 12, 12608-12620, 2010. 
Walser, M. L., Park, J., Gomez, A. L., Russell, A. R., and Nizkorodov, S. A.: Photochemical aging of secondary organic aerosol particles generated from the oxidation of d-limonene, J. Phys. Chem. A, 111, 1907-1913, 2007.

Warnke, J., Bandur, R., and Hoffmann, T.: Capillary-HPLC-ESIMS/MS method for the determination of acidic products from the oxidation of monoterpenes in atmospheric aerosol samples, Analyt. Bioanalyt. Chem., 385, 34-45, 2006.

Yasmeen, F., Vermeylen, R., Szmigielski, R., Iinuma, Y., Boge, O., Herrmann, H., Maenhaut, W. and Claeys, M.: Terpenylic acid and related compounds: precursors for dimers in secondary organic aerosol from the ozonolysis of alpha- and beta-pinene, Atmos. Chem. Phys., 10, 9383-9392, doi:10.5194/acp-10-93832010, 2010.
Yu, J. Z., Cocker, D. R., Griffin, R. J., Flagan, R. C., and Seinfeld, J. H.: Gas-phase ozone oxidation of monoterpenes: Gaseous and particulate products, J. Atmos. Chem., 34, 207-258, 1999.

Zhang, Y. Y., Muller, L., Winterhalter, R., Moortgat, G. K., Hoffmann, T., and Pöschl, U.: Seasonal cycle and temperature dependence of pinene oxidation products, dicarboxylic acids and nitrophenols in fine and coarse air particulate matter, Atmos. Chem. Phys., 10, 7859-7873, doi:10.5194/acp-10-7859-2010, 2010. 